\title{
Ameliorating effects of aged garlic extracts against $A \beta$-induced neurotoxicity and cognitive impairment
}

\author{
Ji Hee Jeong ${ }^{1}$, Hee Rok Jeong ${ }^{1,2}$, Yu Na Jo ${ }^{1}$, Hyeon Ju Kim ${ }^{1}$, Jeong Hae Shin ${ }^{3}$ and Ho Jin Heo ${ }^{1 *}$
}

\begin{abstract}
Background: In vitro antioxidant activities and neuron-like PC12 cell protective effects of solvent fractions from aged garlic extracts were investigated to evaluate their anti-amnesic functions. Ethyl acetate fractions of aged garlic had higher total phenolics than other fractions.

Methods: Antioxidant activities of ethyl acetate fractions from aged garlic were examined using 2,2'-azino-bis (3-ethylbenzthiazoline-6-sulfonic acid) diammonium salt (ABTS) and malondialdehyde (MDA) inhibitory effect using mouse whole brain homogenates. Levels of cellular oxidative stress as reactive oxygen species (ROS) accumulation were measured using 2',7'-dichlorofluorescein diacetate (DCF-DA). PC12 cell viability was investigated by 3-[4,5-dimethythiazol-2-yl]-2,5-diphenyl tetrazolium bromide (MTT) and lactate dehydtrogenase (LDH) assay. The learning and memory impairment in institute of cancer research (ICR) mice was induced by neurotoxic amyloid beta protein (A $B$ ) to investigate in vivo anti-amnesic effects of aged garlic extracts by using Y-maze and passive avoidance tests.

Results: We discovered that ethyl acetate fractions showed the highest ABTS radical scavenging activity and MDA inhibitory effect. Intracellular ROS accumulation resulting from A $\beta$ treatment in PC12 cells was significantly reduced when ethyl acetate fractions were presented in the medium compare to PC12 cells which was only treated with A $\beta$ only. Ethyl acetate fractions from aged garlic extracts showed protection against $A \beta$-induced neurotoxicity. Pre-administration with aged garlic extracts attenuated $A \beta$-induced learning and memory deficits in both in vivo tests.
\end{abstract}

Conclusions: Our findings suggest that aged garlic extracts with antioxidant activities may improve cognitive impairment against $A \beta$-induced neuronal deficit, and possess a wide range of beneficial activities for neurodegenerative disorders, notably Alzheimer's disease (AD).

Keywords: Aged garlic, Amyloid beta protein, Cognitive impairment, Dimethyl disulfide, Neurotoxicity

\section{Background}

According to the World Health Organization (WHO), $5 \%$ of men and $6 \%$ of women aged above 60 years suffer from dementia such as Alzheimer's disease (AD). In addition, AD can also afflict young individual as early as 40 years of age [1]. AD is one of the most serious threats to human health in aged societies of developed countries, and is one of the major neurodegenerative diseases, which is characterized as loss of memory and cognition.

\footnotetext{
* Correspondence: hjher@gnu.ac.kr

${ }^{1}$ Division of Applied Life Science, Institute of Agriculture and Life Science, Gyeongsang National University, Jinju 660-701, Korea

Full list of author information is available at the end of the article
}

In particular, $\mathrm{AD}$ is a progressive disease specified in the brain by the presence of senile plaques rich in insoluble aggregates of amyloid beta protein (A $\beta)$ and neurofibrillary tangles [2]. Accumulated intracellular $\mathrm{A} \beta$-induced oxidative stress including $\mathrm{H}_{2} \mathrm{O}_{2}$ causes peroxidation of membrane lipids and apoptotic cell death by activation of caspases [3,4]. These reactive oxygen species (ROS) also make inflammation or lesions on various organs, and are associated with various degenerative diseases including cancer, aging, arteriosclerosis and neurodegenerative diseases $[4,5]$. Therefore, AD patient exhibit marked decline in cognitive functions and severe behavioral abnormalities such as irritability, aphasia, apraxia, agnosia and restlessness. However, some phytochemicals from natural plant 
sources like fruits and vegetables may reduce the risk of $\mathrm{AD}$ because of their antioxidant properties diminishing oxidative insults [6].

Garlic (Allium sativum), a member of the lily family, has long been used as a medicinal food ingredient with physiological potential for a long time. In addition, garlic is one of the most widely grown vegetable crops in Asia including China and is also known for its therapeutic uses and as a flavouring agent since ancient times [7]. Previous report showed that garlic together with vitamins $\mathrm{E}$ and $\mathrm{C}$ reduced the incidence of precancerous gastric lesions in a large population in China [8]. Garlic is also considered an effective scavenger of free radicals against various diseases caused by ROS. However, many people cannot freely eat fresh raw garlic (FRG) because of its intense taste and smell even though they know that garlic is good for their health. In addition, the consumption of FRG is often associated with several health hazards, such as stomach and digestion problems [7]. Therefore, different formulations of garlic preparation including aged garlic extract (AGE), dehydrated garlic powder, garlic oil and garlic oil macerate was developed [9].

Aged garlic which is recently available on the market in Korea is one of garlic products expected to have strong antioxidant capacity. It has a soft fruity taste with a nonirritating odor. Aged garlic is produced by ageing whole garlic at high temperature $\left(70^{\circ} \mathrm{C}\right)$ and high humidity $(90 \%$ $\mathrm{RH}$ ) [10]. During ageing process, unstable compounds of fresh garlic including alliin are converted into stable compound including S-allyl cysteine (SAC) and various water soluble compounds with potent antioxidant effect [11]. It was reported that aged garlic contained increased content of total phenolics and stronger in vitro antioxidant activity than raw-garlic [10]. Although aged garlic extract has already been demonstrated that an S-allyl-cysteine as an active compound of aged garlic extract has physiological activities including anti-amnesic effects [12], little is known about learning and memory improving effect of resources due to aged garlic extract. Therefore, the present study was undertaken to investigate beneficial effects of aged garlic extract on $\mathrm{A} \beta$-induced cognitive dysfunction in neuron like PC 12 cells and mice.

\section{Methods}

\section{Materials}

2,2'-azino-bis(3-ethylbenzthiazoline-6-sulfonic acid) diammonium salt (ABTS), potassium persulfate, vitamin $C, \alpha-$ tocopherol, catechin, 2-[4-(2-hydroxyethyl)piperazin-1-yl] ethanesulfonic acid (HEPES), sodium bicarbonate, streptomycin, ferrous sulfate $\left(\mathrm{FeSO}_{4}\right)$, hydrogen peroxide $\left(\mathrm{H}_{2} \mathrm{O}_{2}\right)$, dimethyl sulfoxide (DMSO), penicillin, amyloid $\beta$ protein $\left(\mathrm{A} \beta_{25-35}, \mathrm{~A} 4559\right)$, 3-[4,5-dimethythiazol-2-yl]-2,5-diphenyl tetrazolium bromide (MTT) assay kit, lactate dehydrogenase (LDH) assay kit were purchased from Sigma
Chemical Co (St. Louis, MO, USA). All solvents used were of analytical grade. RPMI 1640 medium and fetal bovine serum was obtained from Gibco BRL (Grand Island, NY, USA).

\section{Sample preparation}

Aged garlic (Allium sativum) was supported by Namhae Garlic Research Institute (Namhae, Korea), in December 2010 and was authenticated by Dr. JH Shin (Namhae Garlic Research Institute). Extraction of aged garlic was prepared by pouring $80 \%$ ethanol $3.5 \mathrm{~L}$ into the bottle containing $1 \mathrm{~kg}$ of aged garlic, and the mixture was steeped at room temperature $\left(20^{\circ} \mathrm{C}\right)$ for 7 days [13], and filtrated. The extract was then concentrated under reduced pressure at $60^{\circ} \mathrm{C}$ using vacuum rotary evaporator. Ethanol extract was sequentially partitioned with $n$-hexane, chloroform, ethyl acetate and water. Four solvent fractions were collected and concentrated with vacuum rotary evaporator. The fractions were frozen and lyophilized. Finally, the fractions were placed in a glass bottle and stored at $-20^{\circ} \mathrm{C}$ until used.

\section{PC12 cell culture}

Neuron-like PC12 cell line was derived from a transplantable rat pheochromocytoma. The cells respond reversibly to nerve growth factor (NGF) by induction of the neuronal phenotype. Cells (KCLB 21721, Korea Cell Line Bank, Seoul, Korea) were propagated in RPMI 1640 medium containing $10 \%$ fetal bovine serum, 50 units $/ \mathrm{mL}$ penicillin and $100 \mu \mathrm{g} / \mathrm{mL}$ streptomycin.

\section{ABTS radical-scavenging activity}

ABTS was dissolved in water to make a concentration of $7 \mathrm{mM}$. ABTS was produced by reacting the ABTS stock solution with $2.45 \mathrm{mM}$ potassium persulfate (final concentration) and allowing the mixture to stand in the dark at room temperature for 12-16 h before use. For the study of samples, the ABTS stock solution was diluted with phosphate-buffered saline $5 \mathrm{mM}, \mathrm{pH} 7.4$ to an absorbance of 0.70 at $734 \mathrm{~nm}$. After the addition of $980 \mu \mathrm{L}$ of diluted ABTS to $20 \mu \mathrm{L}$ of sample, the absorbance reading was taken 5 minutes after the initial mixing [14]. This activity is given as percent ABTS scavenging that is calculated as:

$$
\begin{aligned}
& \text { \% ABTS scavenging activity } \\
& =[(\text { control absorbance }- \text { sample absorbance }) / \\
& \quad(\text { control absorbance })] \times 100
\end{aligned}
$$

\section{Malondialdehyde (MDA) assay using mouse whole brain homogenates}

This assay was carried out to the method described by Jeong et al [15]. The brain of young adult male institute of cancer research (ICR) mice were dissected and 
homogenized in ice-cold Tris-HCl buffer (20 mM, pH 7.4) to produce a $1 / 10$ homogenate. The homogenate was centrifuged at $12,000 \times \mathrm{g}$ for 15 minutes at $4^{\circ} \mathrm{C}$. $1 \mathrm{~mL}$ aliquots of the supernatant were incubated with the test samples in the presence of $10 \mu \mathrm{M} \mathrm{FeSO}_{4}$ and $0.1 \mathrm{mM}$ vitamin $\mathrm{C}$ at $37^{\circ} \mathrm{C}$ for $1 \mathrm{~h}$. The reaction was terminated by addition of $1.0 \mathrm{~mL}$ trichloroacetic acid (TCA) $(28 \%, \mathrm{w} / \mathrm{v})$ and $1.5 \mathrm{~mL}$ thiobarbituric acid (TBA) (1\%, w/v) in succession, and then the solution was heated at $100^{\circ} \mathrm{C}$. After $15 \mathrm{mi}-$ nutes, the color of the MDA-TBA complex was measured at $532 \mathrm{~nm}$. (+)-Catechin, a well-known antioxidant, was used as a positive control. The inhibition ratio (\%) was calculated as follows:

$$
\begin{aligned}
& \% \text { inhibition } \\
& =[\text { (absorbance of control }- \text { absorbance of sample }) / \\
& \quad \text { absorbance of control }] \times 100
\end{aligned}
$$

\section{Measurement of cellular oxidative stress}

Levels of cellular oxidative stress were measured by 2',7'dichlorofluorescein diacetate (DCF-DA). PC12 cells were pretreated with various concentrations of aged garlic for $48 \mathrm{~h}$. Freeze-dried ethyl acetate fraction from aged garlic of various concentrations was dissolved in deionized distilled water. Cells were then treated with or without $A \beta_{25-35}$ for $2 \mathrm{~h}$. At the end of the treatment, cells were incubated in the presence of $50 \mu \mathrm{M}$ DCF-DA for $50 \mathrm{~min}$. After incubation, 2',7'-dichlorofluorescein (DCF) was quantified using a fluorometer (infinite F200, TECAN, NC, USA) with a $485 \mathrm{~nm}$ excitation filter and a $535 \mathrm{~nm}$ emission filter. The results were expressed as percent relative to the oxidative stress level of the control cells, which was set to $100 \%$ [3].

\section{Determination of cell viability}

MTT reduction assay was determined using the in vitro toxicology assay kit. Neuronal PC12 cells were plated at a density of $10^{5}$ cells/well on 96-well plates in $100 \mu \mathrm{L}$ of RPMI. Synthetic $A \beta_{25-35}$ was prepared at a concentration of $1 \mathrm{mM}$ in PBS. The cells were pre-incubated with various fractions obtained from aged garlic for $48 \mathrm{~h}$ before adding of $80 \mu \mathrm{MA} \beta_{25-35}$. The cells were treated with or without $A \beta$ for $3 \mathrm{~h}$. MTT reduction was initiated by adding $10 \mu \mathrm{l}$ MTT stock solution per well. Plates were incubated at $37^{\circ} \mathrm{C}$. After $3 \mathrm{~h}$ incubation, the reaction was stopped by adding $100 \mu \mathrm{l}$ of DMSO. The amount of cellular MTT formazan product was determined by measuring absorbance using a microplate reader (680, Bio-Rad, Tokyo, Japan) at a test wavelength of $570 \mathrm{~nm}$ and a reference wavelength of $690 \mathrm{~nm}$ [16].

Neuronal PC12 cells were precipitated by centrifugation at $250 \times g$ for 4 minutes at room temperature, $100 \mu \mathrm{L}$ of the supernatants was transferred into new wells, and LDH was determined using the in vitro toxicology assay kit. Damage of the plasma membrane was evaluated by measuring the amount of the intra-cellular enzyme LDH released into the medium [3].

\section{Animals}

ICR mice (male, 4 weeks old) were obtained from Samtako Co. (Osan, Korea). The mice were housed two per cage in a room maintained with a $12 \mathrm{~h}$ light-dark cycle, $55 \%$ humidity, and $23-25^{\circ} \mathrm{C}$ temperature. All animals and experimental procedures were approved by the guidelines established by the 'Institutional Animal Care and Use Committee (IACUC) of Gyeongsang National University (certificate: GNU-120409-M0009), and in accordance with the Ethical Committee of Ministry of Health and Welfare, KOREA. Freeze-dried ethyl acetate fraction from aged garlic extract was mixed in water at concentrations of 5,10 , and $20 \mathrm{mg} / \mathrm{kg}$ of body weight. Mice were divided into five groups: (I) control $(n=8)$, (II) $\mathrm{A} \beta(n=8)$, (III) $\mathrm{A} \beta+$ sample $5 \mathrm{mg} / \mathrm{kg}(n=8)$, (IV) $\mathrm{A} \beta+$ sample $10 \mathrm{mg} / \mathrm{kg} \quad(n=8)$ and (V) A $\beta+$ sample $20 \mathrm{mg} / \mathrm{kg}(n=8)$. The mice were allowed free access (ad libitum) to water, in which the fraction had been dissolved for 3 weeks. $A \beta_{25-35}$ was administered by intracerebroventricular (ICV) injection to induce memory impairment. A $\beta$ was dissolved in $0.85 \%(\mathrm{v} / \mathrm{v})$ sodium chloride solution. Each mouse was injected at the bregma with a Hamilton microsyringe (depth, $2.5 \mathrm{~mm}$; injection volume, $5 \mu \mathrm{L}$; dose, $410 \mathrm{pmol}$ per mouse) [3].

\section{Y-maze test}

Recording spontaneous alternation behavior in the Y-maze test was used to assess the immediate working memory performance. The Y-maze test was performed 2 days after the ICV A $\beta$ injection. The maze was made of black-painted plastic, and each arm of the maze was $33 \mathrm{~cm}$ long, $15 \mathrm{~cm}$ high and $10 \mathrm{~cm}$ wide, and was positioned at a constant angle. Each mouse was placed at the end of one arm and allowed to move freely through the maze for $8 \mathrm{~min}$. The series of arm entries was recorded visually, and arm entry was considered to have been completed only when the hind paws of the mouse were placed completely in the arm of the maze. Alternation is defined as successive entries into the three arms in an overlapping triplet set. The percentage alternation was calculated as the ratio of actual to possible alternation (defined as the total number of arm entries minus two), multiplied by $100[3,17]$.

\section{Passive avoidance test}

The passive avoidance test box was divided into two compartments, one illuminated and one dark, with a grid floor. The mice were allowed to move freely through a circular tunnel between the two compartments. During 
the training trial ( 3 days after the ICV A $\beta$ injection), each mouse was placed in the lighted compartment: as soon as it entered the dark compartment, an inescapable electric shock was provided $(0.5 \mathrm{~mA}, 1 \mathrm{sec})$. In the probe trial (4 days after the ICV A $\beta$ injection), which was given 1 day after the training trial, the mouse was again placed in the lighted compartment, and the time until it re-entered the dark compartment was measured (the step-through latency maximum testing limit was $300 \mathrm{sec})$ [3].

\section{Identification of active compounds}

Sulfur compounds in fractions obtained from aged garlic were measured at $195 \mathrm{~nm}$ by a photo diode array detector (Ultimate 3000 series, Dionex, CA, USA). Separation was achieved with a Shiseido $C_{18}$ column $(250 \mathrm{~mm} \times 4.6 \mathrm{~mm}$ id, $5 \mu \mathrm{m}$, Shiseido Co., Tokyo, Japan). The mobile phase consisted of water (A) and acetonitrile (B). The linear gradient as reverse phase condition was $0-60 \%$ (B) in 20 min, at a flow rate of $0.5 \mathrm{~mL} / \mathrm{min}$ and the injection volume was $20 \mu \mathrm{L}$. Main sulfur compounds in aged extract were

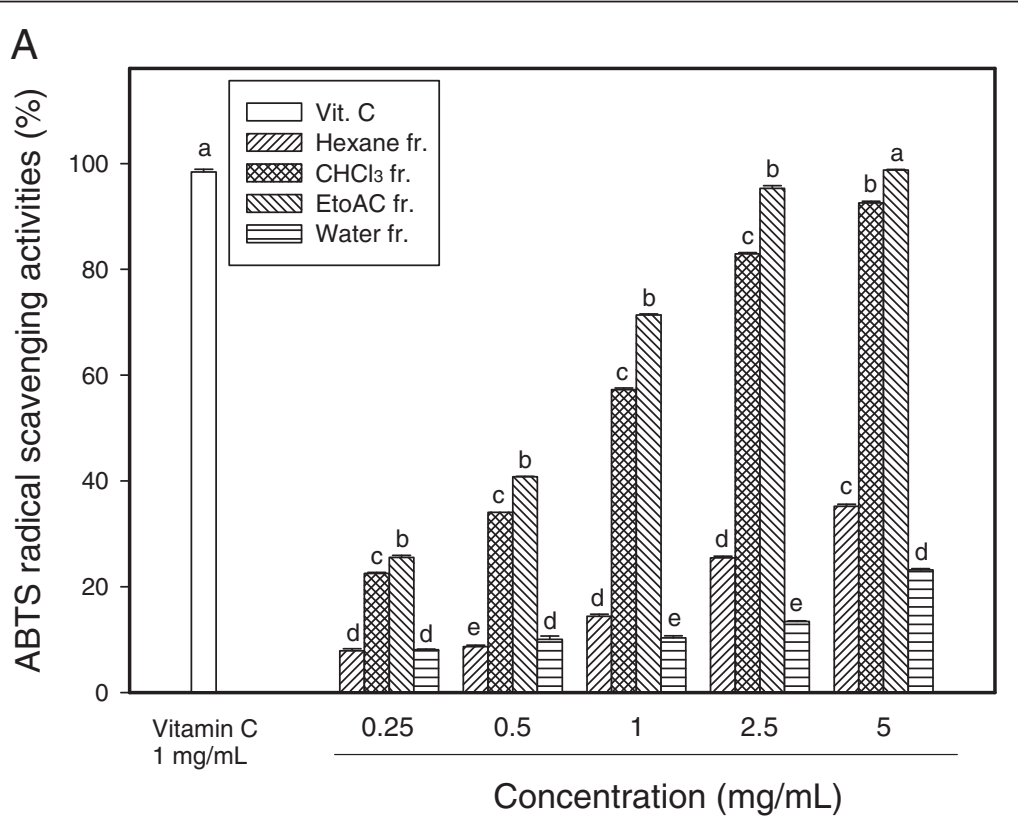

B

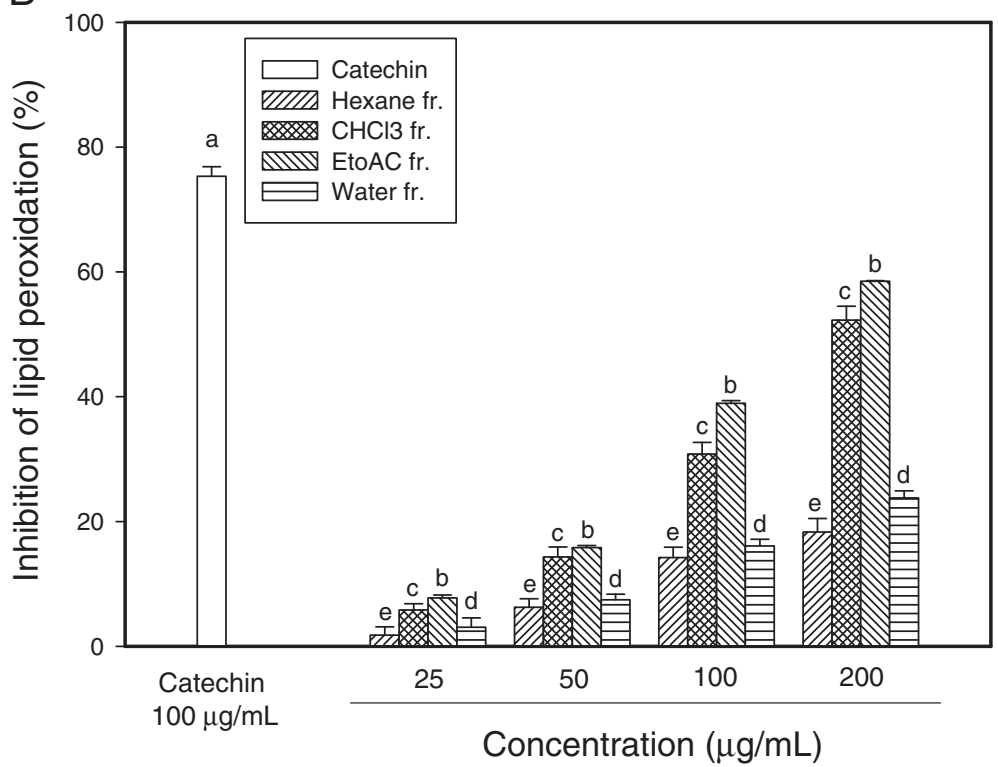

Figure 1 Antioxidant activities. ABTS radical scavenging activities (A) and Inhibition effect of ferric ion and vitaminC-induced lipid peroxidation on mouse brain homogenates (B) of various fractions from aged garlic extracts. Each value represented the means \pm SD of triplicates. Different superscripts indicate significant difference among groups at $p<0.05$. 
identified by comparison of their retention time (RT) values and UV spectra of known standards.

\section{Statistical analysis}

All data were expressed as mean \pm SD. Each experimental set was compared with one-way analysis of variance (ANOVA) and Duncan's multiple-range test $(P<0.05)$ using SAS program (SAS Institute, Cary, NC, USA).

\section{Results}

\section{ABTS radical scavenging activities and inhibition of} lipid peroxidation

The reduction capability of ABTS radical was determined by the decrease in its absorbance at $734 \mathrm{~nm}$, which is induced by antioxidants. Positive ABTS test suggests that aged garlic extracts were free radical scavengers. The extracts exhibited ABTS radical scavenging activities to different extents a concentration-dependent manner. The ethyl acetate fraction exhibited the highest radical scavenging activities when they reacted with the ABTS radical. Although the activity levels of $n$-hexane, chloroform and water were lower than that of ascorbic acid. ABTS radical scavenging effect of the ethyl acetate extracts at $5 \mathrm{mg} / \mathrm{mL}$, which was similar to that of $1 \mathrm{mg} / \mathrm{mL}$ vitamin $\mathrm{C}(p<0.05)$ (Figure 1A). In contrast, the $n$-hexane and water extracts only showed low activities; approximately 3 times lower than the ethyl acetate fraction.

There has been an increasing interest in lipid peroxidation because formation of cytotoxic products such as MDA and 4-hydroxynonenal can influence cellular apoptosis, and several human diseases [18]. Therefore, in this assay, antioxidant activities of aged garlic extracts on vitamin Cinduced lipid peroxidation on mouse whole brain homogenates were also confirmed. Figure $1 \mathrm{~B}$ revealed that the ethyl acetate fraction have excellent activities in suppressing lipid peroxidation on mouse whole brain homogenates. Although the ethyl acetate fraction presented lower than catechin as a positive control at all concentration, it was also noteworthy that more than $50 \%$ of inhibitory activity of lipid peroxidation was observed at the concentration of $200 \mu \mathrm{g} / \mathrm{mL}$.

\section{Measurement of cellular oxidative stress}

The ethyl acetate fraction obtained from aged garlic extract showed prevention of cellular ROS accumulation. Exposure of PC12 cells to $\mathrm{A} \beta$ for two hours resulted in a $144 \%$ increase of oxidative stress levels compared to the control (Figure 2). Pretreatment of PC12 cells by ethyl acetate fraction from aged garlic extract significantly prevented them from intracellular ROS accumulation in comparison to the $\mathrm{PC} 12$ cells treated only with $\mathrm{A} \beta$. PC12 cells at the level of $200 \mu \mathrm{M}$ vitamin $\mathrm{C}$ as a positive control had significantly lower oxidative stress than PC12 cells with treatments of $A \beta$ only (Figure 2 ). In particular, the groups of treatment with $\geq 100 \mu \mathrm{g} / \mathrm{mL}$ showed similar inhibition of oxidative stress to vitamin $\mathrm{C}(p<0.05)$. In this respect, this result suggests that the aged garlic with antioxidant activity may play an important role to reduce the cellular oxidative stress, which is an important risk factor for neurodegenerative diseases such as AD.

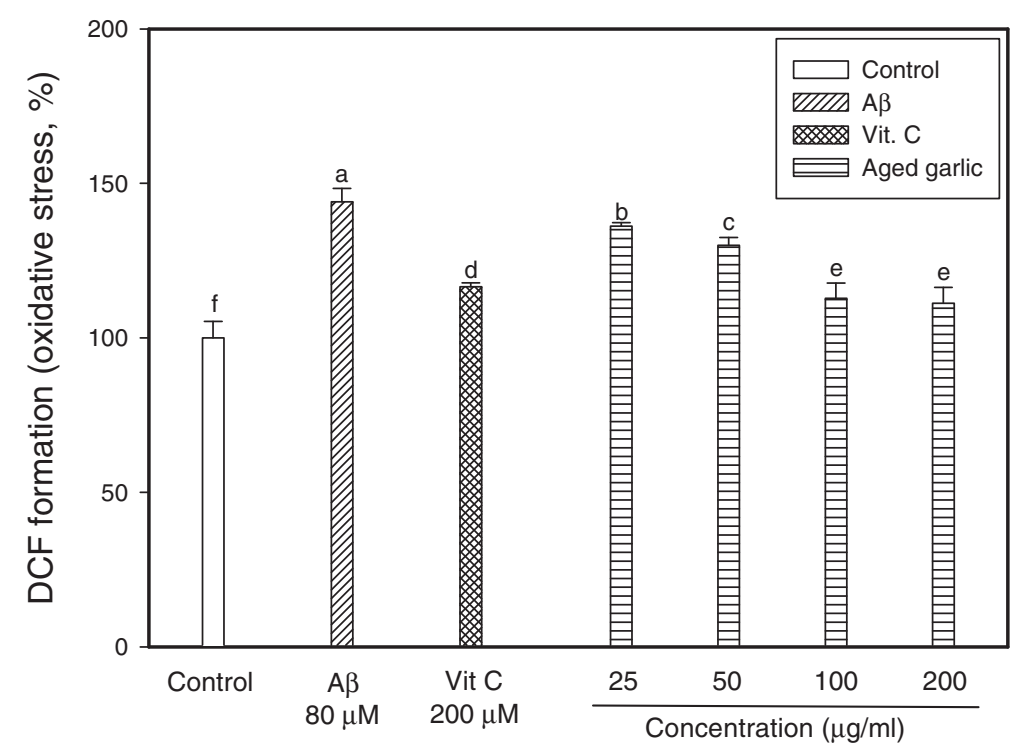

Figure 2 Effect of ethyl acetate fraction from aged garlic extract on ROS production determined in the presence and absence of $A \beta$ in PC12 cell. PC12 cells were pretreated for $48 \mathrm{~h}$ with various concentrations. After $48 \mathrm{~h}$, the cells were treated with $80 \mu \mathrm{M} \mathrm{A \beta}$ for $2 \mathrm{~h}$. The increase of DCF-DA fluorescence was measured by fluorescence microplate reader. Each value represented the means \pm SD of triplicates. Different superscripts indicate significant difference among groups at $p<0.05$. 


\section{PC12 cell protection against $A \beta$-induced neurotoxicity}

The MTT assay relies primarily on the mitochondrial metabolic capacity of viable cells and reflects the intracellular redox state. Cultured PC12 cells were treated with $A \beta_{25-35}$ for $3 \mathrm{~h}$, and the $A \beta$-induced neurotoxic effect was examined by the MTT reduction assay. A $\beta$ treatment caused a decrease in cell viability $(80 \mu \mathrm{M}$; about $56 \%)$. Pretreatment cell with ethyl acetate fraction from aged garlic extracts inhibited $\mathrm{A} \beta$-induced cytotoxicity (Figure 3A).
PC12 cell protective effect of the ethyl acetate fraction at all concentration on oxidative injury was similar to that of $200 \mu \mathrm{M}$ vitamin $\mathrm{C}(p<0.05)$. This study demonstrated that PC12 cell cytotoxicity through $\mathrm{A} \beta_{25-35}$-induced neurotoxicity was suppressed by pretreatment with ethyl acetate fraction obtained from aged garlic.

To investigate the probability of $A \beta$-induced membrane damage, we have assessed the protective effect of the ethyl acetate fraction using the LDH assay, measuring

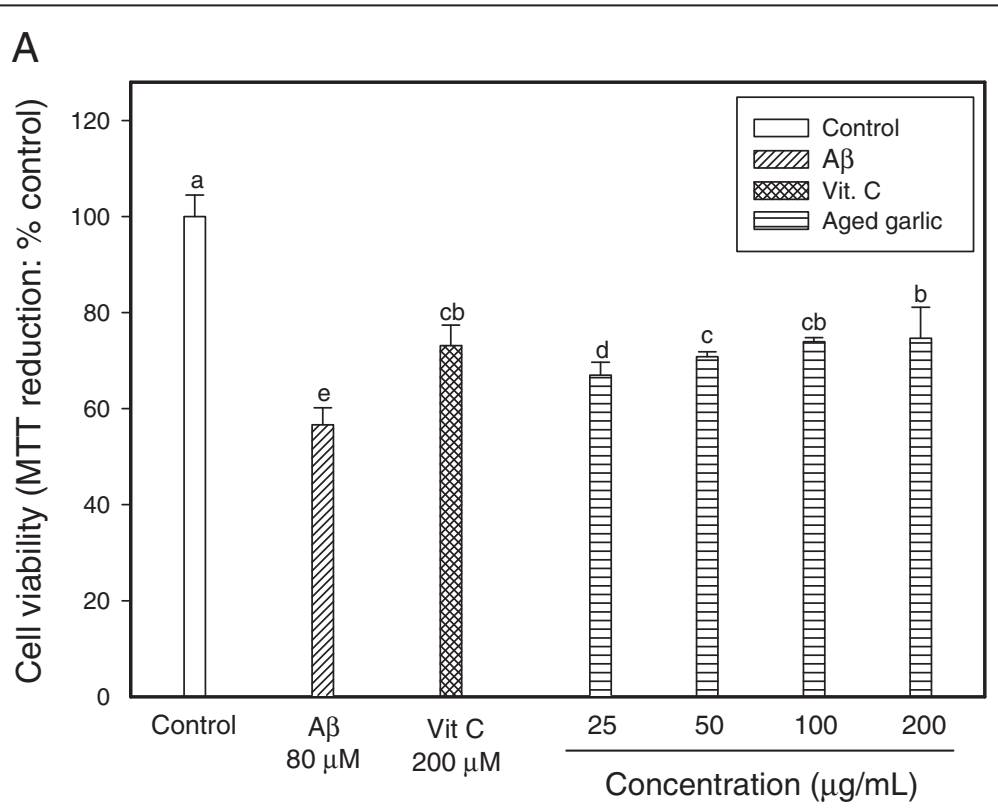

B

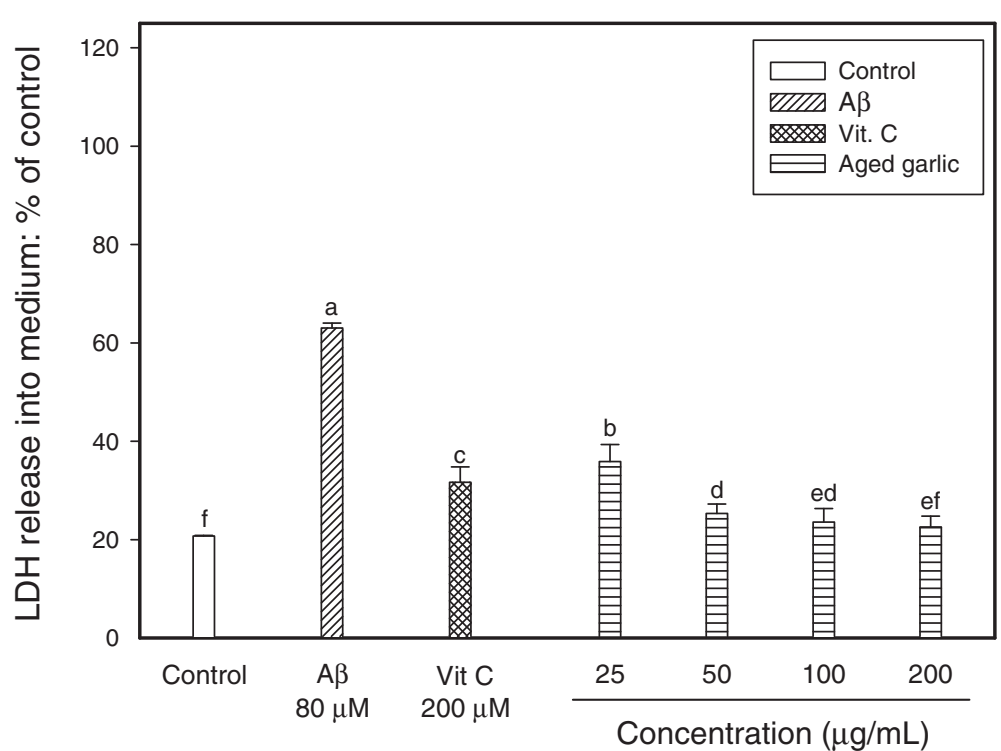

Figure 3 Neuroprotective effect of ethyl acetate fraction from aged garlic extract on A $\beta$-induced cytotoxicity in PC12 cells. (A) Protective effect of the ethyl acetate fraction on A $\beta$-induced cytotoxicity in PC12 cell system. PC12 cells were pretreated for $24 \mathrm{~h}$ with various concentrations. After $24 \mathrm{~h}$, the cells were treated with $80 \mu \mathrm{M}$ A $\beta$ for $3 \mathrm{~h}$. (B) Inhibitory effect of the ethyl acetate fraction on A 3 -induced membrane damage in PC12 cells. PC12 cells were pretreated for $48 \mathrm{~h}$ with various concentrations. After $48 \mathrm{~h}$, the cells were treated with $80 \mu \mathrm{M} A \beta$ for $3 \mathrm{~h}$. Each value represented the means \pm SD of triplicates. Significant difference $(p<0.05$ versus vitamin $C)$ was observed on the A $\beta$-induced cell death. 
the activity of this stable enzyme released into the medium from apoptotic PC12 cells. LDH assay provided an estimate of the percentage of surviving PC12 cells. The ethyl acetate fraction protected the integrity of the cellular membrane at all the concentrations tested (Figure $3 \mathrm{~B}$ ). With $A \beta_{25-35}$ treatment for $3 \mathrm{~h}$, the amounts of $\mathrm{LDH}$ release of PC12 cells increased up to $42 \%$ compared to that of the control without treatment. Our results indicate that ethyl acetate fraction from aged garlic extract protects the PC12 cell membrane against $\mathrm{A} \beta$-induced neurotoxicity.

\section{Anti-amnesic activities against ICV $A \beta$ injection}

The effect of dietary administration of ethyl acetate fraction from aged garlic extract on anti-amnesic effect perception was examined using an AD animal model based on an ICV A $\beta$ injection. Memory and learning abilities were evaluated in a $\mathrm{Y}$-maze test and a passive avoidance task. In Figure $4 \mathrm{~A}$, the $\mathrm{A} \beta_{25-35}$ injected mice exhibited a significantly impaired spatial working memory $(25.93 \%$ decrease in alternation behavior) compared with that of control group (100\%). The groups which were pretreated with the sample increased spontaneous alternation

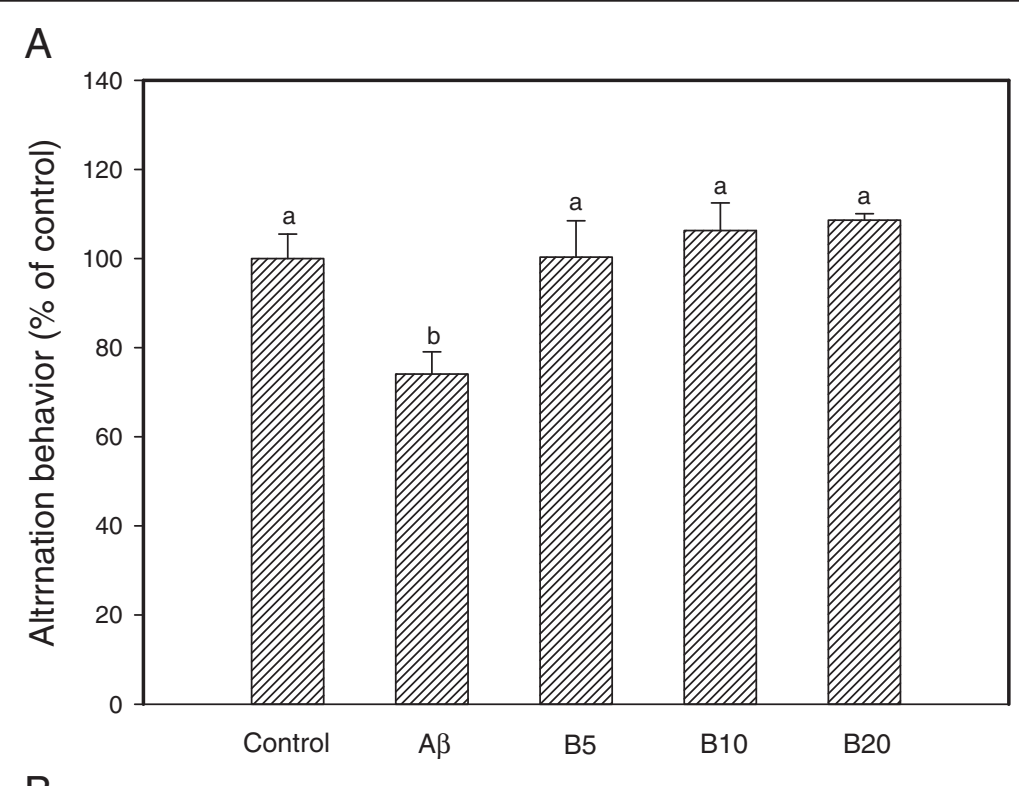

B

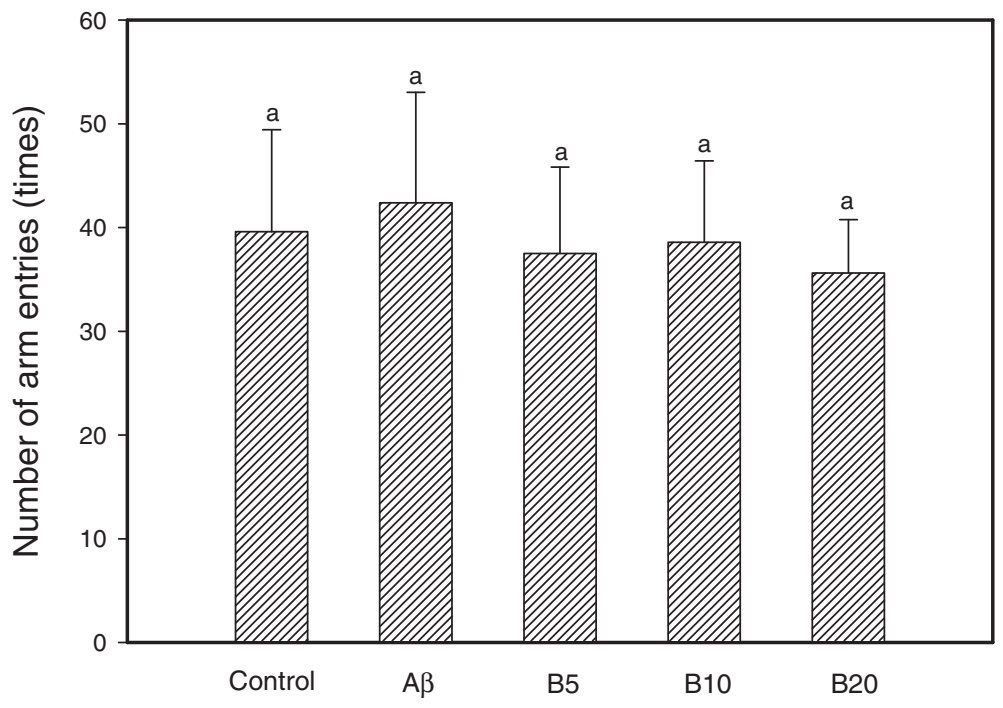

Figure 4 Effect of ethyl acetate fraction from aged garlic extract on spontaneous alternation behavior. Control group was injected with saline (0.85\%). $A \beta_{25-35}$ was injected with 410 pmol of $A \beta_{25-35}$ per mouse. Sample groups were injected $A \beta_{25-35}$ followed by feeding with the ethyl acetate fraction (B5-B20: 5, 10 and $20 \mathrm{mg} / \mathrm{kg}$ per day, respectively). The sample was dissolved in water. The spontaneous alternation behavior (A) and number of arm entries (B) of Y-maze were measured over 8 min. Values indicate the mean $\pm S D(n=8) . p<0.05$ versus control group, $p<0.05$ versus $A \beta_{25-35}$ group. Values with the same letter are not significantly different. 
behavior after $A \beta$ injection (the ethyl acetate fraction $5 \mathrm{mg} / \mathrm{kg}$ : B5, 100.30\%; $10 \mathrm{mg} / \mathrm{kg}$ : B10, 106.33\%; $20 \mathrm{mg} / \mathrm{kg}$ : B20, 108.60\%). In contrast, the number of arm entries did not change among all the experimental group, which demonstrated that general locomotor activity was not affected by $\mathrm{A} \beta_{25-35}$ (Figure $4 \mathrm{~B}$ ).

As shown in Figure 5, mice treated with ethyl acetate fraction from aged garlic extract exhibited attenuated $A \beta-$ induced impairment in a dose-dependent manner. The passive avoidance test was carried out 4 days after $A \beta_{25-35}$ injections. The $A \beta$ injected mice displayed a significant reduction (an $81.07 \%$ decrease) in step-through latency compared with the control group. Ethyl acetate fraction from aged garlic extract attenuated the $\mathrm{A} \beta$-induced impairment of mice in the passive avoidance test. Therefore, these results indicate that ethyl acetate fraction from aged garlic extract displayed a significant anti-amnestic effect in the AD mouse model.

\section{Analysis of sulfur compounds by high performance liquid chromatography (HPLC)}

Since the ethyl acetate fraction exhibited the strongest antioxidant activity, PC12 cell protective activity and in vivo ameliorating effect, it was subjected to further analysis by HPLC to find physiological main compounds. By comparing the retention time and UV spectra of these compounds with those of standard, a dimethyl disulfide anhydrus as main thiosulfate was identified (Figure 6). Consequently, depending on the versatile extraction conditions, the main ingredient of garlic extract will be variously presented sulphide compounds such as a dimethyl disulfide which was identified in the ethyl acetate fraction of aged garlic extract.

\section{Discussion}

Antioxidants can be referred to as reductants, which are inactivating oxidants. They are involved in redox reactions in which on reaction species (oxidant) is reduced at the expense of the oxidation of the antioxidant (reductant) [19]. Oxidative stress caused by increased accumulation of ROS has been implicated in neurodegenerative diseases such as AD [20]. Oxidative stress in AD may result from aging, energy deficiency, inflammation or excessive production of $A \beta$. Amyloid $\beta$ protein can induce cell death through a mechanism involving hydrogen peroxide [20,21]. Neurotoxic properties are characteristic not only of the whole $A \beta$ peptide $A \beta_{1-40(42)}$, but also of a number of fragments, the most neurotoxic of which is fragment $\mathrm{A} \beta_{25-35}$. Furthermore, $A \beta_{25-35}$ is more rapidly toxic and causes more oxidative damage than the parent peptide $\mathrm{A} \beta_{1-42}$. The neurotoxic activity of $\mathrm{A} \beta$ has been attributed to amino acids present in positions $25-35$ of the full-length beta-amyloid [22-24]. Intracellular oxidative stress levels were evaluated by measuring fluorescent DCF formation in PC12 cells. The foregoing experiments, intracellular oxidative stress resulting from $\mathrm{A} \beta$ treatment was significantly lower when PC12 cells were treated with the ethyl acetate fraction from aged garlic extract compared with cells treated only with $A \beta$. These results demonstrate that the ethyl acetate fraction from aged garlic extract

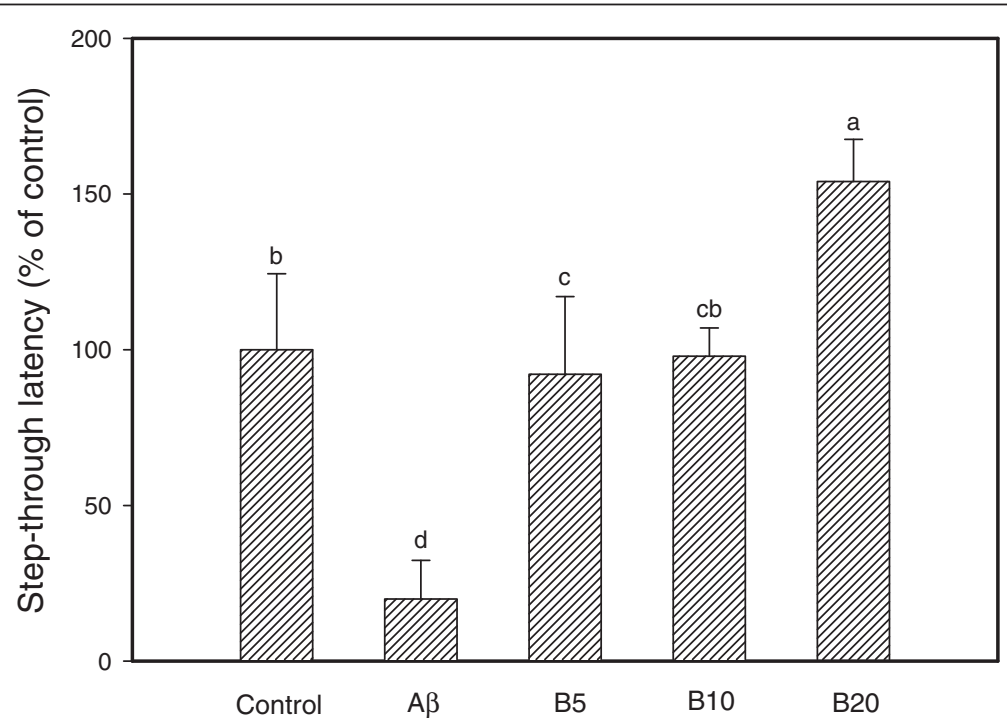

Figure 5 Protective effects of ethyl acetate fraction from aged garlic extract against $A \beta$-induced memory impairment in mice. Control group was injected with saline (0.85\%). $A \beta_{25-35}$ was injected with 410 pmol of $A \beta_{25-35}$ per mouse. For further explanation see the legend to Figure 4. Values indicate the mean $\pm S D(n=8) . p<0.05$ versus control group, $p<0.05$ versus $A \beta_{25-35}$ group. Values with the same letter are not significantly different. 


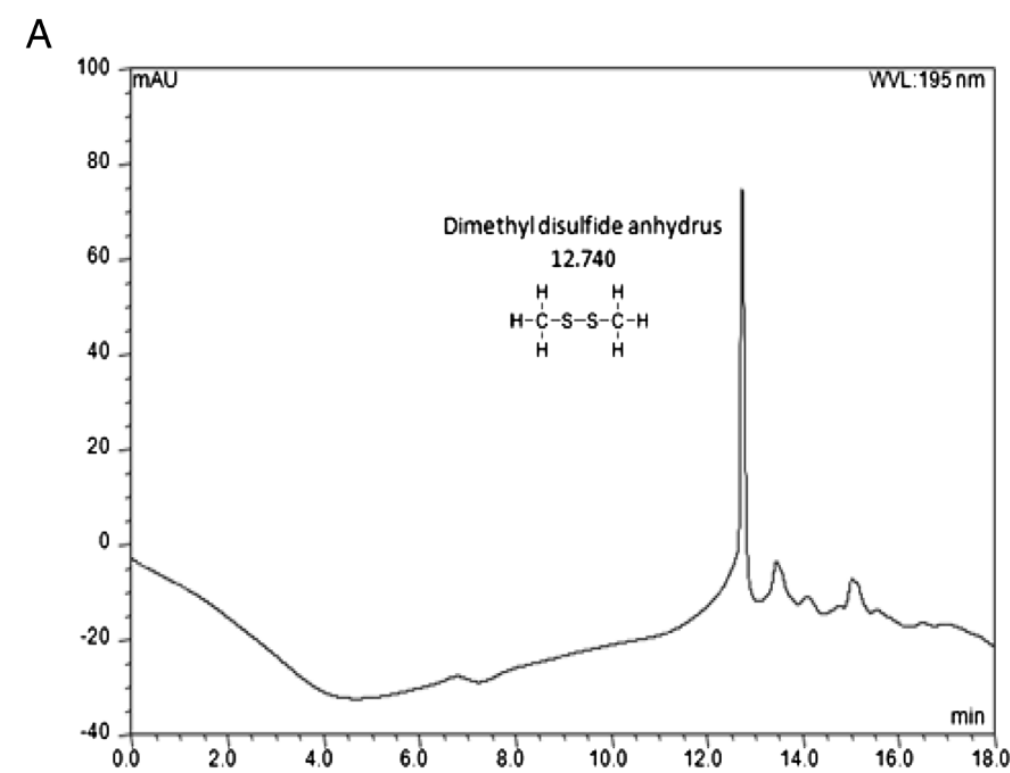

B

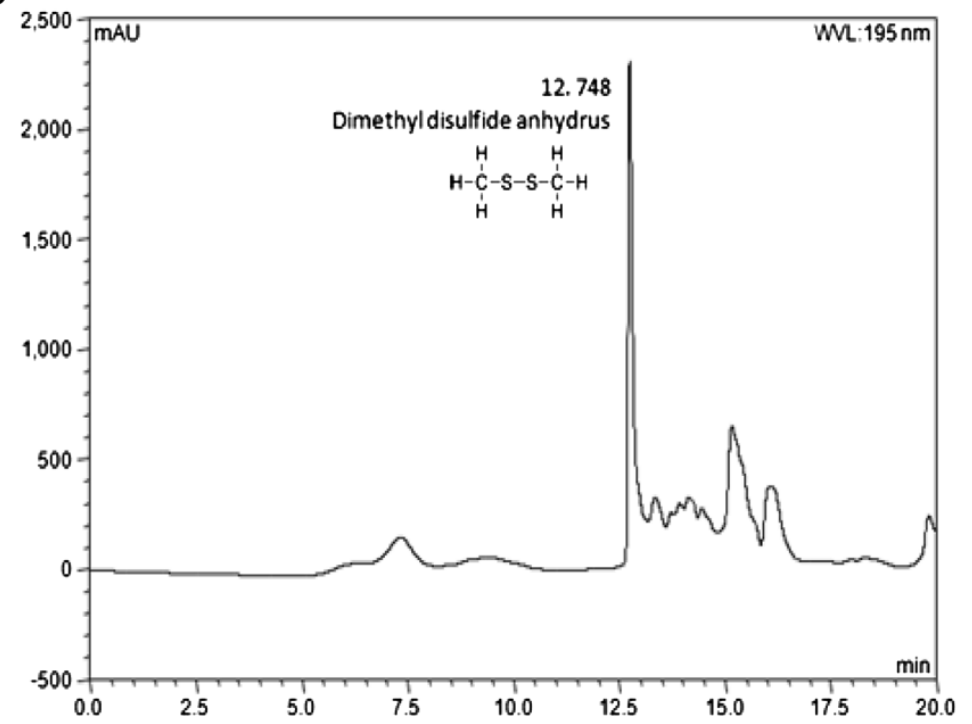

Figure 6 HPLC chromatogram of ethyl acetate fraction from aged garlic. HPLC chromatogram of standards (A) and ethyl acetate fraction (B) from aged garlic at $195 \mathrm{~nm}$.

protected PC12 cells from $\mathrm{A} \beta_{25-35}$-induced ROS generation in vitro.

Deposits of $A \beta$ and neurofibrillary tangles are the two pathological hallmarks of AD. There is recent evidence that $\mathrm{A} \beta$ aggregates can impair function, morphology and subsequently the viability of neuronal cells [21]. Amyloid $\beta$ protein, in the form of insoluble fibril deposits, is the important constituent of senile plaques in $\mathrm{AD}$ patients, and it has been suggested to be the cause of the neurodegeneration that occurs in $\mathrm{AD}$ brains [2]. To evaluate $\mathrm{A} \beta$ neurotoxicity properly, it is important to employ an appropriate method for quantitating cell viability. $A \beta_{25-35}$ has neurotoxicity and produces free radical adducts in aqueous solutions and sensitizes neurons to injury resulting from oxidative stress-induced neurotoxicity induced by glutamate or free radicals [25]. The assay with MTT, a yellow water-soluble tetrazolium salt, is a simple colorimetric assay to measure cell cytotoxicity. This assay has been shown repeatedly to be a very sensitive indicator of the cell death induced by $A \beta$ [2]. Our data showed that $A \beta_{25-35}$ caused a decrease in cell viability, but pretreating ethyl acetate fraction from aged garlic extract inhibited $\mathrm{A} \beta$-induced neurotoxicity in a dose-dependent manner. Oh et al. [22] also treated PC12 cells with $A \beta_{25-35}$, and measured cell viability by an MTT reduction assay. The viability of PC12 cells after treatment with $A \beta_{25-35}(20-80 \mu \mathrm{M})$ for $48 \mathrm{~h}$ decreased 
in a dose-dependent manner to $82.0 \%(20 \mu \mathrm{M}), 53.0 \%$ $(40 \mu \mathrm{M}), 48.8 \%(60 \mu \mathrm{M})$, and $40.4 \%(80 \mu \mathrm{M})$. Therefore, these results demonstrate that $\mathrm{PC} 12$ cell protection by ethyl acetate fraction from aged garlic extract is in part due to the mitochondrial protection mechanism.

Lipid peroxidation is increased in neurodegenerative diseases such as AD. Polyunsaturated fatty acid levels, especially arachidonic acid and docosahexaenoic acid, are high in neuronal cells of brain. They are more vulnerable to attack by ROS, peroxidation of which can lead to changes in membrane integrity and fluidity [16]. Because the neuronal plasma membrane is sensitive to oxidative stress, the cell membrane protective effect of ethyl acetate fraction from aged garlic extracts on $\mathrm{A} \beta$-induced neurotoxicity was investigated by the LDH release assay, measuring the activity of this stable enzyme released into the medium from apoptotic PC 12 cells. Our results indicate that ethyl acetate fraction from aged garlic extract protects the PC12 cell membrane against $\mathrm{A} \beta$-induced neurotoxicity.

The $A \beta_{25-35}$-induced disruption in hippocampal network activity correlates with a reduction in spontaneous neuronal activity and synaptic transmission, as well as with an inhibition in the sub-threshold oscillations produced by pyramidal neurons in vitro [23]. The effect of dietary administration of ethyl acetate fraction from aged garlic extract on behavioral abilities was examined using and $\mathrm{AD}$ animal model based on an intracerebroventricular $A \beta$ injection. Memory and learning abilities were evaluated in a Y-maze test and a passive avoidance task. The mouse model was used to measure $A \beta$-induced memory impairment. This suggests that in mice, exposure to the $A \beta$ fragment cause impairments in the learning and memory systems. It has also been reported that antioxidants can protect against $A \beta$-peptide-induced toxicity [3]. In this study, we have shown that in mice, the $A \beta_{25-35}$-induced cognitive deficits exerted via various cytotoxicities including oxidative stress and disruption of hippocampal network activity are suppressed by pretreatment with aged garlic.

The major volatile compounds of garlic were sulfur containing compounds. Okada [26] studied structure antioxidant activity relationship for thiosulfinates and suggested that the combination of the allyl group $\left(-\mathrm{CH}_{2} \mathrm{CH}=\mathrm{CH}_{2}\right)$ and the $-\mathrm{S}(\mathrm{O}) \mathrm{S}$ - group is necessary for the antioxidant action of thiosulfinates in the garlic extract. Major volatiles of raw and heated garlic were dimethyl disulfide, 2-propen1-ol, allyl methyl disulfide, dimethyl trisulfide, diallyl disulfide, allyl methyl trisulfide, and diallyl trisulfide. However, a dimethyl disulfide (DMDS), which was not observed in raw garlic samples, was just observed in heated samples (autoclaved garlic clove and autoclaved-crushed), indicating thermal reaction may cause the formation of this compound [27]. Storing sliced raw garlic in 15\%-20\% ethanol for 20 months produces AGE. This whole process is supposed to cause a considerable loss of allicin and to increase the activity of certain newer compounds, such as SAC, Sallylmercaptocysteine, allixin and selenium which are stable, highly bioavailable and significantly antioxidant [28]. Our study demonstrated that PC12 cell cytotoxicity through $\mathrm{A} \beta_{25-35}$-induced neurotoxicity was suppressed by pretreatment with ethyl acetate fraction obtained from ethanolic extract of aged garlic. In our research, we showed that ethyl acetate fraction form ethanolic garlic extract had in vitro antioxidant activities, PC12 cell protections, and in vivo anti-amnesic effects. Ito $\mathrm{Y}$ et al. [29] also demonstrated that SAC also protected cultured hippocampal neurons against A $\beta$-induced neuronal death. In this study, we have shown that aged garlic extract containing various compounds with DMDS is considered that may be helpful to overcome $A \beta-$ induced cognitive impairment and cytotoxicity.

DMDS was identified as one with greater concentration toward the mix of volatiles. The abundance (\%) of DMDS was about $30 \%$ in volatile compounds from Smethyl cysteine sulfoxide. However contents of DMDS may be changed, depending on samples (fresh garlic, aged garlic, and aged garlic oil etc.) [11,30]. Since the cumulative concentration of organosulfides which was consumed in aged garlic extracts is high, it is likely that the combined concentrations of ingested organosulfides may reach levels high enough to bring about a cellular response and cognitive improvement in mice.

\section{Conclusions}

Anti-amnesic effects of ethyl acetate fraction from aged garlic extract on learning and memory deficits were evaluated with in vitro/vivo animal models. We discovered from our present work that among fractions of the extract, the ethyl acetate fraction has the highest levels of in vitro antioxidant activities and neuroprotective effect against A $\beta$-induced cytotoxicity in neuron-like PC12 cells. Moreover, biochemical experiments using whole brain tissues clearly showed lowered oxidative stress levels, and ethyl acetate fraction from aged garlic extract attenuated both memory and cognitive ability against $A \beta$-induced deficits. Therefore, the physiological activities of ethyl acetate fraction from aged garlic extracts may be attributed to sulfide compounds which include dimethyl disulfide anhydrus.

\footnotetext{
Abbreviations

ABTS: 2,2'-azino-bis(3-ethylbenzthiazoline-6-sulfonic acid) diammonium salt; MDA: Malondialdehyde; ROS: Reactive oxygen species; DCF-DA: 2',7'dichlorofluorescein diacetate; MTT: 3-[4,5-dimethythiazol-2-yl]-2,5-diphenyl tetrazolium bromide; LDH: Lactate dehydtrogenase; ICR: Institute of cancer rese; A 3 : Amyloid beta protein; AD: Alzheimer's disease; AGE: Aged garlic extract; FRG: Fresh raw garlic; DMSO: Dimethyl sulfoxide; NGF: Nerve growth factor; TCA: Trichloroacetic acid; TBA: Thiobarbituric acid; IACUC: Institutional animal care and use committee; HPLC: High performance liquid chromatography; RT: Retention time; ICV: Intracerebroventricular; SAC: S-allyl cysteine; DMDS: Dimethyl disulfide.
}

\section{Competing interests}

The authors declare that they have no competing interests. 


\section{Authors' contributions}

$\mathrm{HJH}$ participated in the design of the study. JHJ, HRJ, YNJ and HJK conducted the experiments, analyzed the data and drafted the manuscript. JHS helped conduct the experiments. All authors read and approved the final version of the manuscript.

\section{Acknowledgments}

This work was supported by the National Research Foundation of Korea Grant funded by the Korean Government (KRF-2011-0021664) and the Technology Development Program for Regional Industry of Namhae Garlic Research Institute, Republic of Korea (2011). J. H. Jeong, Y. N. Jo and H. J. Kim were supported by BK21 program (MEST).

\section{Author details}

${ }^{1}$ Division of Applied Life Science, Institute of Agriculture and Life Science, Gyeongsang National University, Jinju 660-701, Korea. ${ }^{2}$ Department of Analytical research, Pacificpharma Corporation, Anseong 456-370, Republic of Korea. ${ }^{3}$ Namhae Garlic Research Institute, Namhae, South Korea.

Received: 20 June 2013 Accepted: 8 October 2013

Published: 18 October 2013

\section{References}

1. Fratiglioni L, Winblad B, Strauss EV: Prevention of Alzheimer's disease and dementia. Major findings from the Kungsholmen project. Physiol Behav 2007, 92:98-104

2. Varadarajan S, Yatin S, Aksenova M, Butterfield DA: Review: Alzheimer's amyloid $\beta$ - peptide-associated free radical oxidative stress and neurotoxicity. J Struct Biol 2000, 130:184-208.

3. Choi SJ, Kim MJ, Heo HJ, Kim JK, Jun WJ, Kim HK, Kim EK, Kim MO, Cho HY, Hwang HJ, Kim YJ, Shin DH: Ameliorative effect of

1,2-benzenedicarboxylic acid dinonyl ester against amyloid beta peptide-induced neurotoxicity. Amyloid 2009, 16:15-24.

4. Valencia A, Morán J: Reactive oxygen species induce different cell death mechanisms in cultured neurons. Free Radic Biol Med 2004, 36:1112-1125.

5. Choi HR, Choi JS, Han YN, Bae SJ, Chung HY: Peroxynitrite scavenging activity of herb extracts. Phytother Res 2002, 16:364-367.

6. Youdim KA, Joseph JA: A possible emerging role of phytochemicals in improving age-related neurological dysfunctions: a multiplicity of effects. Free Radic Biol Med 2001, 30:583-594.

7. Butt MS, Sultan MT, Butt MS, lqbal J: Garlic: nature's protection against physiological threats. Crit Rev Food Sci Nutr 2009, 49:538-551.

8. Zheng $L$, Rujing $L$, Hsiang $T$, Huang J: Host range and phytotoxicity of Stemphylium solani, causing leaf blight of garlic (Allium sativum) in China. Eur J Plant Pathol 2009, 124:21-30.

9. Butt MS, Sultan MT: Levels of trans fats in diets consumed in developing economies. J AOAC Inter 2009, 92:1277-1283.

10. Jang EK, Seo JH, Lee SP: Physiological activity and antioxidative effects of aged black garlic (Allium sativum L.) extract. K J Food Sci Technol 2008, 40:443-448.

11. Kaschula $\mathrm{CH}$, Hunter R, Parker Ml: Garlic-derived anticancer agents: structure and biological activity of ajoene. Biofactors 2010, 36:78-85.

12. Ray $B$, Chauhan NB, Lahiri DK: Oxidative insults to neurons and synapse are prevented by aged garlic extract and S-allyl-L-cysteine treatment in the neuronal culture and APP-Tg mouse model. J Neurochem 2011, 117:388-402.

13. Sultana S, Ripa FA, Hamid K: Comparative antioxidant activity study of some commonly used spice in Bangladesh. Pakistan J Biol Sci 2010 , 13:340-343.

14. Jeong CH, Choi GN, Kim JH, Kwak JH, Kim DO, Kim YJ, Heo HJ: Antioxidant activities from the aerial parts of Platycodon grandiflorum. Food Chem 2010, 118:278-282.

15. Jeong $\mathrm{CH}$, Jeong HR, Choi GN, Kim DO, Lee UK, Heo HJ: Neuroprotective and anti-oxidant effects of caffeic acid isolated from Erigeron annuus leaf. Chin Med 2011, 6:25.

16. Kim JH, Choi GN, Kwak JH, Jeong HR, Jeong CH, Heo HJ: Neuronal cell protection and acetylcholinesterase inhibitory effect of the phenolics in chestnut inner skin. Food Sci Biotechnol 2011, 20:311-318.

17. Heo HJ, Kim MJ, Lee JM, Choi SJ, Cho HY, Hong B, Kim HK, Kim E, Shin DH: Naringenin from Citrus junos has an inhibitory effect on acetycholinesterase and a mitigating effect on amnesia. Dement Geriatr Cogn Disord 2004, 17:151-157.

18. Sevanian A, Ursini F: Lipid peroxidation in membranes and low-density lipoproteins: similarities and differences. Free Radic Biol Med 2000, 29:306-311.

19. Siddhuraju P, Manian S: The antioxidant activity and free radical-scavenging capacity of dietary phenolic extracts from horse gram (Macrotyloma uniflorum (Lam.) Verdc.) seeds. Food Chem 2007, 105:950-958.

20. Smith MA, Rottkamp CA, Nunomura A, Raina AK, Perry G: Oxidative stress in Alzheimer's disease. Biochim Biophys Acta-Mol Cell Res 2000, 1502:139-144.

21. Walsh DM, Selkoe DJ: A $\beta$ oligomers - a decade of discovery. J Neurochem 2007, 101:172-1184

22. Oh YJ, Kim EY, Kim YH, Jin JZ, Jin BK, Jahng GH, Jung MH, Park C, Kang IS, Ha JH, Choe WC: Neuroprotective effects of overexpressed cyclophilin B against $A \beta$ - induced neurotoxicity in PC12 cells. Free Radical Biol Med 2011, 51:905-920.

23. Peña F, Ordaz B, Balleza-Tapia B, Bernal-Pedraza R, Márquez-Ramos A Carmona-Aparicio L, Giordano M: Beta-Amyloid Protein (25-35) Disrupts Hippocampal Network Activity: Role of Fyn-Kinase. Hippocampus 2010, 20:78-96.

24. Lu P, Mamiya T, Lu L, Mouri A, Ikejima I, Kim HC, Zou LB, Nabeshima T: Xanthoceraside attenuates amyloid $\beta$ peptide25-35-induced learning and memory impairments in mice. Psychopharmacol (Berl) 2012, 219:181-190.

25. Klegeris A, McGeer PL: $\beta$-amyloid protein enhances macrophage production of oxygen free radicals and glutamate. J Neurosci Res 1997 49:229-235

26. Okada Y, Tanaka K, Fujita Sato E, Okajima H: Antioxidant activity of thiosulfinates derived from garlic. Redox Rept 2005, 7:96-102.

27. Kim NY, Park MH, Jang EY, Lee JH: Volatile Distribution in Garlic (Allium sativum L.) by Solid Phase Microextraction (SPME) with Different Processing Conditions. Food Sci Biotechnol 2011, 20:775-782.

28. Banerjee SK, Mukherjee PK, Maulik SK: Garlic as an antioxidant: the good, the bad and the ugly. Phytother res 2003, 17:97-106.

29. Ito $Y$, Kosuge $Y$, Saakikubo T, Horie K, Ishikawa N, Obokata N, Yokoyama E, Yamashina K, Yamamoto M, Saito H, Arakawa M, Ishige K: Protective effect of S-allyl-L-cysteine, a garlic compound, on amyloid b-protein-induced cell death in nerve growth factor-differentiated PC12 cells. Neurosci Res 2003, 46:119-125.

30. Vargas-Arispuro I, Corrales-Maldonado C, Martinez-Tellez MA: Compounds derived from garlic as bud induction agents in organic farming of table grape. Chil J Agr Res 2008, 68:94-101.

\section{doi:10.1186/1472-6882-13-268}

Cite this article as: Jeong et al:: Ameliorating effects of aged garlic extracts against $A \beta$-induced neurotoxicity and cognitive impairment. BMC Complementary and Alternative Medicine 2013 13:268.

\section{Submit your next manuscript to BioMed Central and take full advantage of:}

- Convenient online submission

- Thorough peer review

- No space constraints or color figure charges

- Immediate publication on acceptance

- Inclusion in PubMed, CAS, Scopus and Google Scholar

- Research which is freely available for redistribution 